\title{
ANALISIS STRATEGI PELUANG USAHA FASHION WANITA PADA TOKO AII COLECTION DI KOTA BANDAR LAMPUNG
}

\author{
Strategy Analysis of Women's Fashion Business Opportunity at Aii Colection Shop in \\ Bandar Lampung City
}

\author{
Suhartina ${ }^{1}$, Riska Gita Utami ${ }^{2}$, Soewito $^{3}$ \\ Program Studi Administrasi Bisnis, FISIP, Universitas Tulang Bawang Lampung \\ suhartina@utb.ac.id
}

\begin{abstract}
Aii Collection is a fashion store in the clothing business that focuses on fulfilling the needs of women, located on Jln. Pangeran Antasari, Number 8B, Bandar Lampung City. This study analyzes the strategies that can be carried out in order to increase women's fashion business opportunities at the Aii Collection store. The purpose of this research is to find out what strategies can be done to increase sustainable business opportunities at the Aii Colection store by using qualitative research methods. Data collection techniques are field research and interviews, which clearly describe how these factors are interrelated in the Aii Collection effort by analyzing using SWOT analysis and IFE EFE matrix tools. From the research results, SWOT matrix analysis and SWOT cartesius diagram shows that the Aii collection effort is in quadrant $I$, with values (1.92 and 1.55). Where is a situation that will benefit and it is known that the company is still a developing company. The best strategy that can be applied to the Aii Collection business is the aggressive strategy or the Growth Oriented Strategy.
\end{abstract}

Keywords: IFE EFE, strategy, business opportunities, SWOT

\begin{abstract}
ABSTRAK
Aii Colection merupakan salah satu toko fashion dibidang usaha pakaian yang berfokus pada pemenuhan kebutuhan wanita yang terletak di Jln. Pangeran Antasari, Nomor 8B, Kota Bandar Lampung. Penelitian ini menganalisis tentang Bagaimana strategi yang dapat dilakukan dalam rangka meningkatkan peluang usaha fashion wanita pada toko Aii Colection. Tujuan penelitian ini yaitu untuk mengetahui strategi apa yang dapat dilakukan untuk menambah peluang usaha yang berkelanjutan pada toko Aii Colection dengan metode penelitian secara kualitatif. Teknik pengumpulan data yaitu dengan penelitian lapangan dan Interview, yang menggambarkan secara jelas tentang bagaimana faktor-faktor tersebut saling berkaitan pada usaha Aii Colection dengan dilakukan analisis menggunakan analisis SWOT dan alat bantu matrik IFE EFE. Dari hasil penelitian analisis matrik SWOT dan diagram cartesius SWOT menunjukan bahwa usaha Aii Colection berada dikuadran I, dengan nilai (1,92 dan 1,55). Dimana merupakan keadaan yang akan menguntungkan dan diketahui perusahaan masih termasuk perusahaan berkembang. Strategi terbaik yang dapat diaplikasikan pada usaha Aii Colection ini adalah strategi agresif atau Growth Oriented Strategy.
\end{abstract}

Kata kunci: IFE EFE, strategi, peluang usaha, SWOT 


\section{Pendahuluan}

Bisnis dibidang fashion adalah usaha yang sudah lama dijalankan mulai dari pedesaan sampai ibukota, dalam usaha fashion persaingan pun semakin ketat, para pelaku usaha di tuntut untuk meningkatkan penjualan dan menambah peluang usaha agar dapat terus memenangkan hati konsumen demi kelangsungan perusahaan. Untuk menemukan peluang usaha fashion maka dibutuhkan sebuah analisa tentang bagaimana peluang-peluang yang ada, yang nantinya akan menggambarkan tentang bagaimana faktor-faktor yang saling berkaitan pada usaha Aii Colection. Aii Colection merupakan salah satu toko fashion dibidang usaha pakaian yang berfokus pada pemenuhan kebutuhan wanita. Aii Colection memulai usahanya pada pertengahan tahun 2016. Produk yang dijual di Aii Colection meliputi berbagai macam model dan motif yang beraneka ragam, Beberapa produk yang dijual di toko Aii colection yaitu meliputi aneka jenis pakaian (berupa one set, tunik, dress, celana) tas, dan hijab. Menurut (Barusman et al., n.d.) pemilik usaha dituntut mampu mengembangkan suatu metode guna menciptakan strategi usaha agar konsumen mendapatkan nilai lebih dari suatu barang atau merek produk, dan mampu mempertahankan kualitas produk. Selain itu, banyaknya pesaing yang sudah lama bergerak di bidang yang sama membuat usaha ini mengalami turun naik dalam hal penjualannya, untuk itulah diperlukan sebuah strategi agar menambah peluang usaha yag ada agar tetap berjalan mengikuti trend saat ini. Strategi yang harus dilakukan pelaku bisnis selama ini dalam meningkatkan peluang usaha yaitu dengan memberikan pelayanan yang baik, lokasi yang dapat dijangkau, keterjangkauan harga, kebersihan dan kenyamanan sehingga untuk meningkatkan penjualan serta peluang usaha yang ada dan ditambah dengan dilakukannya promosi. Promosi perlu dilakukan untuk memperkenalkan suatu produk. Menurut (Dunan et al., n.d.) Tujuan dari promosi guna menciptakan kesadaran, meningkatkan minat, menambah penjualan, serta menumbuhkan loyalitas merek suatu produk. Sehingga untuk meningkatkan penjualan serta peluang usaha yang ada maka dapat dilakukan dengan strategi pemasaran. Pada Tabel 1 menunjukan data penjualan sebagai berikut:

Tabel 1. Data penjualan Produk toko Aii Colection Periode Januari - September 2020.

\begin{tabular}{lll}
\hline No & \multicolumn{1}{c}{ Bulan } & \multicolumn{1}{c}{ Jumlah } \\
\hline 1. & Januari & Rp. 607.747.000 \\
2. & Februari & Rp. 638.342.790 \\
3. & Maret & Rp. 688.306.342 \\
4. & April & Rp. 552.279.786 \\
5. & Mei & Rp. 1.045.698.519 \\
6. & Juni & Rp. 505.732.213 \\
7. & Juli & Rp. 762.397.951 \\
8. & Agustus & Rp. 855.055.053 \\
9. & September & Rp. 710.622.736 \\
\hline
\end{tabular}

Sumber : Aii Colection 
Pada Tabel 1. diatas, menunjukan bahwa usaha Aii Colection saat ini sedang tidak stabil dan mengalami naik turunnya penjualan. Dalam hal ini untuk meningkatkan penjualan dan peluang usaha diperlukan strategi yang tepat, agar usaha Aii Colection dapat Stabil.

\section{Tinjauan Pustaka}

(Redaputri \& Barusman, 2018) berpendapat bahwa "Strategi merupakan suatu tindakan oleh seseorang atau suatu perusahaan dalam pencapaian suatu tujuan yang telah di tentukan". Pendapat (Rahayu \& Retnani, 2016) strategi diartikan suatu cara dalam mencapai suatu target karna didalam sebuah manajemen strategi merupakan suatu kebutuhan untuk perusahaan dalam mencapai target suatu perusahaan. Pokok strategi manajemen ialah menemukan tujuan dari organisasi, dan sumber daya yang ada dipakai secara efektif guna memenuhi target dalam strategi. (Yunus, 2016) berpendapat bahwa "manajemen strategi ialah mampu memberikan dasar dalam pengambilan keputusan organisasi".

Menurut (Yohana, 2015) peluang usaha merupakan tempat keperluan pembeli, dimana pelaku usaha bisa mengelola usaha tersebut guna mendapatkan keuntunganan. Menurut (Aprilianty, 2013) Wirausahawan merupakan seseorang yang dapat mengembangkan produk baru, ide baru dengan konsep baru.

(Tambunan, 2020) berpendapat bahwa "SWOT ialah memberikan pemahaman bagaimana perusahaan harus menyesuaikan bermacam kegiatan internalnya dengan keadaan eksternalnya secara urutan dalam mencapai target yang diharapkan". Menurut (Oetomo, 2012) analisis SWOT ialah rencana strategis dengan mengunakan faktor-faktor internal dan eksternal sehingga nantinya akan memberikan cara sederhana dalam menerapkan strategi. matriks Swot bisa menghasilkan 4 (empat) set kemungkinan alternatif stratetegis (Ramadhan \& Sofiyah, n.d.). matriks SWOT ialah yang artinya Strenght (kekuatan), Weakness (kelemahan), Opportunities (peluang), Threats (hambatan), pengertiannya adalah suatu alat bantu yang dipakai dalam merangkai faktor-faktor strategi di perusahaan serta menggambarkan bagaimana peluang opportunity dan threats dapat dilakukan perusahaan sehingga bisa disesuaikan dengan strenght dan weakness yang dimiliki.

\section{Metodologi Penelitian}

Dalam penelitian ini, teknik pengumpulan data yaitu dengan cara:

1. Penelitian kepustakaan, penelitian ini diterapkan untuk mempelajari teori, konsep-konsep yang didapat dari berbagai media, seperti buku bacaan, literature, karya tulis, dan mengumpulkan data serta informasi dari berbagai media yang sah. Sebagai dasar teori dalam penulisan karya ilmiah ini.

2. Penelitian lapangan, Merupakan teknik pengumpulkan data atau informasi dengan melakukan pengamatan secara langsung pada objek penelitian dengan cara:

a. Observasi

mengumpulan data atau informasi secara langsung ke Toko Aii Colection.

b. Interview

Teknik pengumpulan data yang dilakukan dengan cara mengajukan pertanyaan yang berkaitan dengan strategi peluang usaha kepada pemilik toko dan pada konsumen Aii colection.

c. Dokumentasi 
Teknik pengumpulan data yang dilakukan dengan menggunakan dokumen tertulis (hasil penelitian, laporan tertulis, buku literatur, majalah, jurnal, dan sebagainya) sebagai sumber data penelitian dengan cara melakukan pengelompokan atau klasifikasi data yang berhubungan dengan masalah penelitian.

\section{Metode Analisis}

Metode analisis yang digunakan pada penelitian ini adalah metode analisis kualitatif. Pendekatan kualitatif menekankan proses atau sifat realita yang berarti tidak diteliti dengan begitu ketat atau terukur, tetapi dilihat dari quality, banyaknya, serta intensitas. Dengan menggunakan metode kualitatif ini ingin memperoleh gambaran mendalam mengenai objek yang akan diteliti dengan berpedoman pada pendekatan teoritis. Dan penelitian ini menggunakan alat analisis yaitu dengan analisis SWOT serta matrik IFE dan EFE. Menurut (Kunci \& Rangkuti, 2004) Metode analisis SWOT yaitu untuk menemukan faktor internal dan eksternal, yang meliputi upaya-upaya dari faktor-faktor internal dan eksternal sehingga dapat mengetahui kinerja perusahaan. Informasi data eksternal dan internal dapat diperoleh dari berbagai sumber.

\section{Hasil Dan Pembahasan}

Dalam penelitian ini, faktor-faktor masalah dari eksternal dan internal di identifikasi untuk mengetahui yang menjadi faktor kekuatan dan kelemahan. Setelah faktor faktor tersebut dalam usaha Aii Colection diketahui, selanjutnya dapat ditata ke dalam tabel matrik IFE dan EFE. Penyusunan matrik IFE yaitu untuk menentukan faktor internal yang merupakan kekuatan dan kelemahan, Sedangkan matriks EFE guna menentukan faktor dari eksternal yang merupakan peluang dan ancaman pada usaha Aii Colection. Selanjutnya tiaptiap faktor diberi bobot dengan skala mulai dari 0,0 (Tidak penting) sampai 1,0 (Sangat penting) yang mana semua bobot tersebut tidak melebihi skor keseluruhan 1,00. Faktor faktor tersebut kemungkinan memiliki dampak pada usaha Aii Colection, Setelah tiap-tiap faktor diberi bobot, langkah berikutnya adalah menghitung rating dari tiap-tiap faktor dengan diberi skala mulai dari 1 (dibawah rata-rata) hingga dengan 4 (sangat baik). Sehingga sesudah melakukan pembobotan dan rating tiaptiap faktor, selanjutnya adalah mengalikan bobot tiap tiap faktor dengan rating tiap-tiap faktor untuk mendapatkan nilai skor. 
Tabel 2. Identifikasi SWOT

\begin{tabular}{|c|c|}
\hline \multicolumn{2}{|c|}{ FAKTOR INTERNAL } \\
\hline KEKUATAN (STRENGTH) & KELEMAHAN (WEAKNESS) \\
\hline $\begin{array}{l}\text { 1. Kualitas produk menggunakan bahan premium. } \\
\text { 2. Menjual produk dengan harga yang terjangkau. } \\
\text { 3. Memberikankonsumen berupa discount atau potongan harga. } \\
\text { 4. Lokasi perusahaan mudah dijangkaukarena sudah berada } \\
\text { 5. Sitengah kota dan pusat keramaian } \\
\text { 5. karyawan yangramah dan solutif kepada konsumen. }\end{array}$ & $\begin{array}{l}\text { 1. Sulitnya menentukan produk baru. } \\
\text { 2. Banyak permintaan darikonsumen yang } \\
\text { tidak terpenuhi.| } \\
\text { 3. Konten yangkurangmenarik } \\
\text { 4. Kurangannya SDM dari karyawan } \\
\text { 5. Sering terjadi perbedaan pendapat antar } \\
\text { karyawan. }\end{array}$ \\
\hline \multicolumn{2}{|c|}{ FAKTOR EKSTERNAL } \\
\hline PELUANG (OPPORTUNITY) & ANCAMAN (THREAT) \\
\hline $\begin{array}{l}\text { 1. Perusahaan bisa memiliki peluang untuk meningkatkan } \\
\text { penjualan dengan memperluas pemasaran. } \\
\text { 2. daya beli meningkat karena jumlah konsumen yang datang } \\
\text { terus meningkat sehingga akan membuka peluang pangsa } \\
\text { konsumen. } \\
\text { 3. kemajuan teknologi dapat memberikan dampak yang } \\
\text { menguntungkan. }\end{array}$ & $\begin{array}{l}\text { 1. Persaingan antara kualitas produk dari } \\
\text { model, maupun bentuk yang serupa. } \\
\text { 2. Tidak memperluas usaha. } \\
\text { 3. Banyaknya pendatang usaha baruyang } \\
\text { bermunculan. }\end{array}$ \\
\hline
\end{tabular}

Sumber: Hasil wawancara.

Tabel 3. Perhitungan faktor IFE (Internal Faktor Evaluasi)

\begin{tabular}{|c|c|c|c|c|}
\hline No & FAKTOR INTERNAL & BOBOT & RATING & SKOR \\
\hline \multicolumn{5}{|c|}{ STRENGHT (KEKUATAN) } \\
\hline 1. & Kualitas produk menggunakan bahan premium. & 0,16 & 4 & 0,64 \\
\hline 2. & Menjual produk dengan harga yang terjangkau & 0,12 & 4 & 0,48 \\
\hline 3. & Memberikan konsumen berup a discount atau potongan harga. & 0,12 & 3 & 0,36 \\
\hline 4. & $\begin{array}{l}\text { Lokasi perusaha an mudah dijangkau karena sudah berada } \\
\text { ditengah kota dan pusat keramaian }\end{array}$ & 0,12 & 4 & 0,48 \\
\hline 5. & Sikap karyawan yangramah dan solutif kepada konsumen & 0,16 & 3 & 0,48 \\
\hline & SUB TOTAL & 0,68 & & 2,44 \\
\hline \multicolumn{5}{|c|}{ WEAKNESS (KELEMAHAN) } \\
\hline 1. & Sulitny a menentukan produk baru. & 0,08 & 2 & 0,16 \\
\hline 2. & Banyak permintaan dari konsumen yang tidak terpenuhi. & 0,08 & 2 & 0,16 \\
\hline 3. & Konten yangkurangmenarik & 0,08 & 1 & 0,08 \\
\hline 4. & Kurangannya SDM dari karyawan & 0,04 & 2 & 0,08 \\
\hline 5. & Sering terjadi perbedaan pendapat antarkaryawan. & 0,04 & 1 & 0,04 \\
\hline & SUB TOTAL & 0,32 & & 0,52 \\
\hline & TOTAL & 1,00 & & 2,96 \\
\hline
\end{tabular}

Sumber: Data diolah 2021 
Dari perhitungan Tabel 3. IFE (internal

Factor Evaluasi) diatas, maka dapat dilihat faktor strenght memiliki nilai skor 2,44 sementara weakness memiliki nilai skor 0,52 .sedangkan untuk nilai skor keseluruhan diperoleh 2,96.

Tabel 4. Perhitungan faktor EFE (Eksternal Faktor Evaluasi)

\begin{tabular}{|c|c|c|c|c|}
\hline No & FAKTOR EKSTERNAL & BOBOT & RATING & SKOR \\
\hline \multicolumn{5}{|c|}{ OPPORTUNITIES (PELUANG) } \\
\hline 1. & $\begin{array}{l}\text { Perusahaan bisa memiliki peluang untuk meningkatkan penjualan } \\
\text { denganmemperluas pemasaran }\end{array}$ & 0,22 & 3 & 0,66 \\
\hline 2. & $\begin{array}{l}\text { Daya beli meningkat karena jumlah konsumen yang datang terus } \\
\text { meningkat sehingga akanmembuka peluang pangsa konsumen. }\end{array}$ & 0,17 & 4 & 0,68 \\
\hline 3. & kemajuan teknologi dapat memberikan dampak yangmenguntungkan & 0,22 & 4 & 0,88 \\
\hline & SUB TOTAL & 0,61 & & 2,22 \\
\hline \multicolumn{5}{|c|}{ THREAT (ANCAMAN) } \\
\hline 1. & $\begin{array}{l}\text { Persaingan antara kualitas produk darimodel, maupun bentuk yang } \\
\text { serupa. }\end{array}$ & 0,17 & 2 & 0,34 \\
\hline 2. & Tidak memperluas usaha. & 0,11 & 1 & 0,11 \\
\hline 3. & Banyaknya pendatang usaha baru yang bermunculan. & 0,11 & 2 & 0,22 \\
\hline & SUB TOTAL & 0,39 & & 0,67 \\
\hline & TOTAL & 1,00 & & 2,89 \\
\hline
\end{tabular}

Sumber: Data diolah 2021

Berdasarkan perhitungan Tabel 4 . Eksternal factor Evaluasi (EFE), diketahui faktor peluang memiliki total nilai skor 2,22 dan ancaman memiliki nilai skor 0,67 sehingga total nilai skor keseluruhan dari faktor ekternal 2.89.

Dari Tabel diatas sehingga diketahui bahwa Faktor internal yang dimiliki oleh usaha Aii Colection lebih besar dari kelemahannya. Dimana kekuatan memiliki skor 2,44 sedangkan kelemahannya memiliki nilai skor 0,52 sedangkan faktor eksternal (peluang) yang dimiliki oleh usaha Aii Colection lebih besar 2,22 dari faktor ancaman nya dengan skor 0.67. Dari perhitungan dapat diperoleh formula strategi pemasaran yang selaras dengan Diagram cartesius analisis SWOT.

Diagram cartesius anallisis SWOT merupakan tahap analisis berikutnya setelah tabel IFE, EFE, setelah diketahui nilai strenght dan weakness maka dengan itu memiliki selisih 1,92 dan nilai peluang diatas threat memiliki selisih 1,55 . Dari identifikasi faktorfaktor tersebut maka dapat kita dilihat diagram cartesius pada gambar 1 dibawah ini adalah sebagai berikut: 
Gambar 1. Diagram Cartesius Analisis SWOT

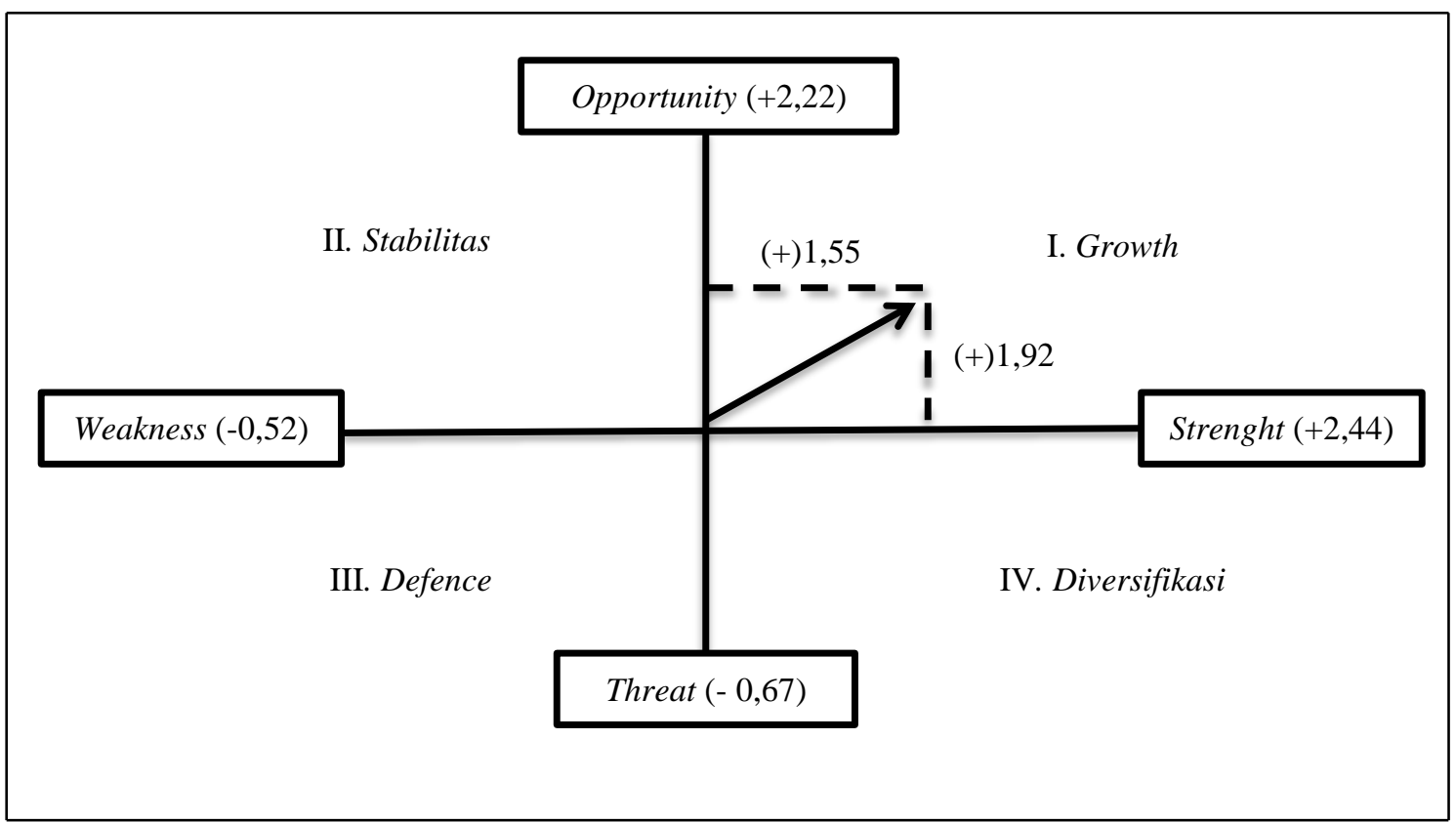

Sumber: Hasil perhitungan penulis.

Dari tabel diatas diketahui diagram cartesius analisis SWOT usaha Aii Colection berada pada dikuadran I, dengan nilai $(1,92$ dan 1,55$)$. dimana kuadran I ialah keadaan yang akan menguntungkan dan menunjukkan usaha Aii Colection masih dalam perusahaan yang berkembang dan mampu mendapatkan keuntungan dari peluang eksternal. Strategi yang dapat digunakan dalam keadaan ini adalah agresif (Growth Oriented Strategy).

Analisis matrik kombinasi SWOT dapat dilihat pada Tabel 5 sebagai berikut ini: 


\section{Tabel 5. Matriks Kombinasi SWOT Aii Colection}

\begin{tabular}{|c|c|c|}
\hline Faktor Internal & \begin{tabular}{|l} 
STRENGHTS (Kekuatan) \\
1. $\begin{array}{l}\text { Kualitas Produk menggunakan Bahan } \\
\text { Premium } \\
\text { 2. }\end{array}$ \\
$\begin{array}{l}\text { Menjual produk dengan harga yang } \\
\text { terjangkau. } \\
\text { 3. Memberikan konsumen berupa } \\
\text { diskon atau potongan harga. }\end{array}$ \\
4. $\begin{array}{l}\text { Lokasi perusahaan mudah dijankau } \\
\text { karena sudah berada ditengah kota } \\
\text { dam pusat keramaian }\end{array}$ \\
5. Sikap karyawan yang ramah dan \\
solutif kepada konsumen.
\end{tabular} & \begin{tabular}{|ll} 
& \multicolumn{1}{c}{ WEAKNESS (Kelemahan) } \\
1. & Sulitnya menentukan produk baru \\
2. & Banyaknya permintaan dari konsumen \\
& yang tidak terpenuhi \\
3. & Konten yang Kurang menarik \\
4. & Kurangnya SDM dari karyawan \\
5. & Sering terjadi perbedaan pendapat abtar \\
& karyawan
\end{tabular} \\
\hline $\begin{array}{l}\text { OPPORTUNITY (Peluang) } \\
\text { 1. Perusahaan bisa memiliki } \\
\text { peluang untuk meningkatkan } \\
\text { penjualan dengan mmeperluas } \\
\text { pemasaran } \\
\text { 2. Daya beli meningkat karena } \\
\text { jumlah konsumen yang datang } \\
\text { terus meningkat sehingga akan } \\
\text { membuka peluang pangsa } \\
\text { konsumen } \\
\text { 3. Kemajuan teknologi dapat } \\
\text { memberikan dampak yang } \\
\text { menguntungkan }\end{array}$ & $\begin{array}{l}\text { STRATEGI-SO } \\
\text { (Strenghts-Opportunity) } \\
\text { (Gunakan kekuatan untuk } \\
\text { memanfaatkan peluang) } \\
\text { Mempertahankan dan } \\
\text { 1. } \quad \begin{array}{l}\text { meningkatkan kualitas produk serta } \\
\text { pelayanan perusahaan dengan } \\
\text { teknologi yang canggih dan } \\
\text { modern }\end{array} \\
\text { 2. Menambah varian produk } \\
\text { Mengevaluasi harga dan } \\
\text { memberikan diskon secara berkala. }\end{array}$ & $\begin{array}{l}\text { STRATEGI-WO } \\
\text { Weakness-Opportunity } \\
\text { Gunakan kelemahan untuk memanfaatkan } \\
\text { peluang). } \\
\text { 1. } \quad \begin{array}{l}\text { Memperluas usaha dengan membuka } \\
\text { cabang usaha baru. }\end{array} \\
\text { 2. } \quad \begin{array}{l}\text { Meningkatkan kualitas produk agar } \\
\text { lebih unggul dari produk bersama }\end{array} \\
\text { seluruh pekerja. } \\
\text { 3. Melakukan promosi secara kontinyu } \\
\text { untuk menarik minat konsumen. }\end{array}$ \\
\hline 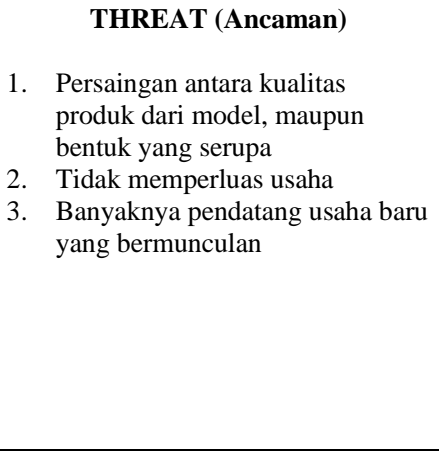 & 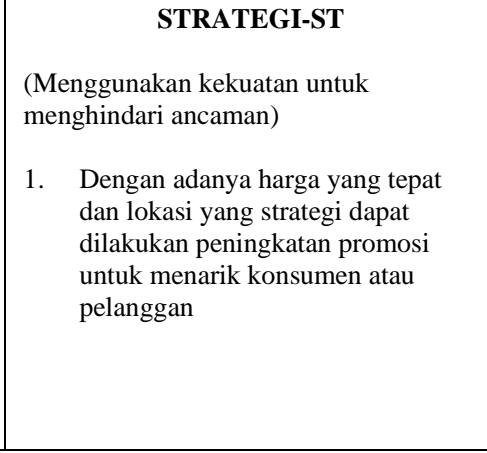 & $\begin{array}{l}\text { STRATEGI-WT } \\
\text { (Gunakan kelemahan untuk menghindari } \\
\text { ancaman) } \\
\text { 1. } \quad \begin{array}{l}\text { Pemilik usaha harus mengevaluasi } \\
\text { secara menyeluruh terkait produk yang } \\
\text { akan dipasarkan, baik dari penyediaan } \\
\text { produk, kualitas produk, yang tentunya }\end{array} \\
\text { lebih baik dari pesaing. } \\
\text { Menambah varian produk dan } \\
\text { meningkatkan kualitas produk agar } \\
\text { konsumen tertarik dengan poduk yang } \\
\text { dijual. }\end{array}$ \\
\hline
\end{tabular}

Sumber : Data diolah 2021 


\section{Kesimpulan Dan Saran}

\section{Kesimpulan}

Dari hasil analisis penelitian dan pada pembahasan ini, Aii colection berada pada kuadran I yaitu berada pada strategi Growth, maka kesimpulanya adalah sebagai berikut :
1. Aii
Colection
dapat mengembangkan kualitas produknya dengan cara meningkatkan kualitas bahan yang akan dipasarkan supaya konsumen lebih tertarik terhadap produk yang dijual oleh Aii Colection, dan memanfaatkan promosi melalui komunikasi pesanpesan yang telah dibuat untuk memperdalam kamunikasi dengan konsumen, untuk menciptakan keterkaitan yang baik dan menciptakan promosi menjadi lebih menarik dalam meningkatan penjualan.

2. Strategi keunggulan Biaya.

Dalam melaksanakan strategi keunggulan Biaya, Aii Colection memungkinkan agar menekan jumlah biaya dengan cara: penentuan harga pokok yang tepat dapat mengontrol biaya pengeluaran dan biaya pemasukan perusahaan. Perusahan juga mampu untuk merancang, membuat serta mempromosikan produk yang setara dengan cara yang lebih efisien dari pada perusahaan pesaingnya

3. Strategi diferensiasi.

Dalam melakukan strategi deferensiasi, Aii Colection melakukan penambahan varian produk baru, baik dari segi model maupun bentuk model.

\section{Saran}

Dalam menerapkan strategi-strategi tersebut sebaiknya, Aii Colection memperhatikan beberapa hal, yaitu:

1. Dalam meningkatkan pengembangan usaha Aii Colection, hal yang harus di perhatikan adalah dengan mempertahankan kualitas produk, menurunkan harga, serta memberikan potongan harga kepada konsumen apabila disetiap pembelian produk yang banyak.

2. Aii Colection sebaiknya melakukan perbaikan pada strategi yang belakanngan ini dilakukan agar tidak tersaingi dengan adanya pesaing baru yang bermunculan. Perbaikan tersebut dapat dilakukan dengan berbagai cara, yaitu dengan melakukan perubahan penetapan dari strategi harga, kualitas produk, dan mengoptimalkan strategi promosi untuk menciptakan loyalitas konsumen. Dalam menentukan harga, Aii Colection disarankan untuk mengkaji lebih mendalam terkait perhitunganperhitungan penentuan harga guna mendapatkan hasil keputusan yang tepat, sehingga dapat menekankan kelebihan biaya pengeluaran perusahaan.

3. Dalam penambahan varian produk sebaiknya untuk menjual produk yang tidak dimiliki oleh pesaing, hal ini dimaksudkan supaya perusahaan Aii Colection memiliki pembeda dengan pesaing, yang tentunya akan lebih menarik minat konsumen. 


\section{DAFTAR PUSTAKA}

Aprilianty, E. (2013). Pengaruh kepribadian wirausaha, pengetahuan kewirausahaan, dan lingkungan terhadap minat berwirausaha siswa SMK. Jurnal Pendidikan Vokasi, 2(3), 311-324. https://doi.org/10.21831/jpv.v2i3.1 039

Barusman, M. Y. S., Salam, T. V., \& Redaputri, A. P. (n.d.). Analisis Strategi Bisnis Marley's Cafe Coffee and Resto Bandar Lampung. 26.

Dunan, H., Antoni, M. R., Jayasinga, H. I., \& Redaputri, A. P. (n.d.). Analisis Faktor-Faktor yang Mempengaruhi Penjualan " Waleu " Kaos Lampung di Bandar Lampung Sumber: Asosiasi Pengusaha Oleh-Oleh Provinsi Lampung. 167-185.

Kunci, K., \& Rangkuti, F. (2004). Zuhrotun Nisak.

Oetomo, Hening Widi;Ardini, L. (2012). Swot Analysis in Strategic Management: a Case Study At Purabaya Bus Station Analisis Swot Dalam Manajemen Strategis : Studi Kasus Pada Terminal Bus Purabaya. Journal of Economics, Business, and Accountancy Ventura, 15(110), 171-186.

Rahayu, D. T., \& Retnani, E. D. (2016). Penerapan Analisis Swot Dalam Perumusan Strategi Bersaing Pada Eddy Jaya Photo Sekolah Tinggi Ilmu Ekonomi Indonesia (STIESIA) Surabaya. Ilmu Dan Riset Akuntansi, 5(2). https://ejournal.stiesia.ac.id/jira/arti cle/viewFile/1638/1599

Ramadhan, A., \& Sofiyah, F. R. (n.d.).
Analisis SWOT sebagai landasan dalam menentukan strategi pemasaran ( studi McDonald' $s$ Ring Road) This research aims to identify and analyze the ma rketing strategy of McDoanald' $s$ Ring Road by using the SWOT analysis consisting of Strength, Weakness .

Redaputri, A. P., \& Barusman, M. Y. S. (2018). Strategi Pembangunan Perekonomian Provinsi Lampung. Jurnal Manajemen Indonesia, 18(2), 86. https://doi.org/10.25124/jmi.v18i2. 1340

Tambunan, T. S. (2020). SWOT Analysis for Tourism Development Strategy of Samosir Regency. TIJAB (The International Journal of Applied Business), 4(2), 90. https://doi.org/10.20473/tijab.v4.i2 .2020.90-105

Yohana, C. (2015). Pelatihan Motivasi Kewirausahaan Dan Menganalisis Peluang Usaha, Membuat Rencana Bisnis Bagi Tenaga Kerja Wanita (Tkw) Purna Di Desa Cibalong Kecamatan Gunung Guruh, Sukabumi-Jawa Barat. Sarwahita, 13(02).

https://doi.org/10.21009/sarwahita. 132.03

Yunus, E. (2016). Buku Manejemen Strategi. 